\title{
Limb salvage after delayed arterial repair in compound Grade III C fracture humerus: a case report
}

\author{
Dhurvas Ramlal Ramprasath*, Major K. Kamalanathan, K. S. Maheswaran, \\ Mohan Prasad Muthsamy
}

Department of Orthopaedic Surgery, Coimbatore Medical College Hospital, Coimbatore, Tamil Nadu, India

Received: 17 August 2017

Revised: 19 September 2017

Accepted: 20 September 2017

\section{*Correspondence:}

Dr. Dhurvas Ramlal Ramprasath,

E-mail: dhurvasramprasath@gmail.com

Copyright: () the author(s), publisher and licensee Medip Academy. This is an open-access article distributed under the terms of the Creative Commons Attribution Non-Commercial License, which permits unrestricted non-commercial use, distribution, and reproduction in any medium, provided the original work is properly cited.

\begin{abstract}
A combination of brachial artery injury and fracture shaft of humerus is a rare phenomenon. There is a general apprehension regarding survival of a limb after vascular injury. Only few studies exist in literature that discuss about the survival of such limbs. Our case is a 56 years old female patient who presented three hours after sustaining injury in the form of fracture shaft of humerus and complete transection of brachial artery distal to the origin of profunda brachii. Even though Doppler USG done initially revealed flow in the vessels distal to the injury, a CT Angiogram done later revealed cutting of the brachial artery. This prompted us to perform brachial artery exploration and repair. post operatively, digital subtraction angiography showed absence of flow in the brachial artery but limb survived due to extensive collateral circulation. Even after the golden period of vascular repair has lapsed, arterial repair is recommended if there is no evidence of gangrene. This should be supplemented with adequate systemic anticoagulants and/or fasciotomy.
\end{abstract}

Keywords: Brachial artery injury, Fracture humerus, Doppler study, Collateral circulation, Gangrene, Delayed repair

\section{INTRODUCTION}

Compound fractures involving shaft of humerus with brachial artery injury is a very rare combination. Patients with such injuries can land up with either amputation or infection. Amputation rates as low as $4 \%$ have been reported with isolated arterial injuries, although rates as high as $61 \%$ have been seen when combined vascular, skeletal and soft tissue injuries are present. ${ }^{1-3} \mathrm{We}$ are presenting such a case which was managed with multidisciplinary approach and limb salvage achieved. The purpose of this presentation is to share our experience and knowledge of management of compound grade III $\mathrm{C}$ fracture shaft of humerus and its results and comparing with literature.

\section{CASE REPORT}

A 56 year old female patient with history of Road Traffic Accident presented to our emergency department after three hours of sustaining injury. The patient was conscious and haemodynamically stable. Local examination of left upper limb revealed lacerated wound (Figure 1) measuring $3 \times 2 \times 1 \mathrm{~cm}$ overlying the brachial artery in the middle third - distal third junction of left arm. Distal pulses could not be felt. There was no neurological deficit. $X$ ray (Figure 2) showed comminuted fracture shaft of humerus. The patient also had compound Grade I fracture both bone left leg.

Immediate colour doppler revealed triphasic flow in axillary, brachial and radial arteries. The ulnar artery 
showed biphasic flow. Immediately patient was shifted to OR and wound debridement along with modular external fixator stabilization of the fracture (Figure 3 ) was done. X ray (Figure 4) showed good alignment of the fracture.

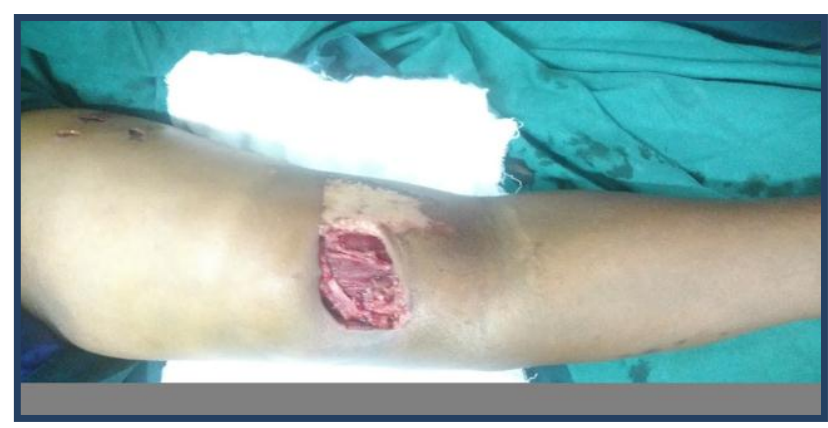

Figure 1: Wound on the anteromedial surface of arm.

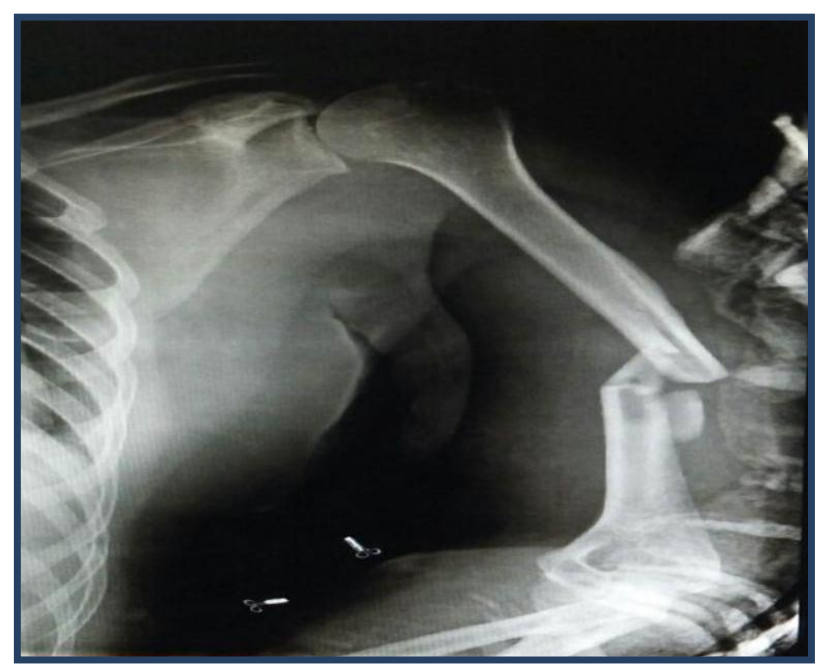

Figure 2: $\mathrm{X}$ ray showing comminuted fracture shaft of humerus.

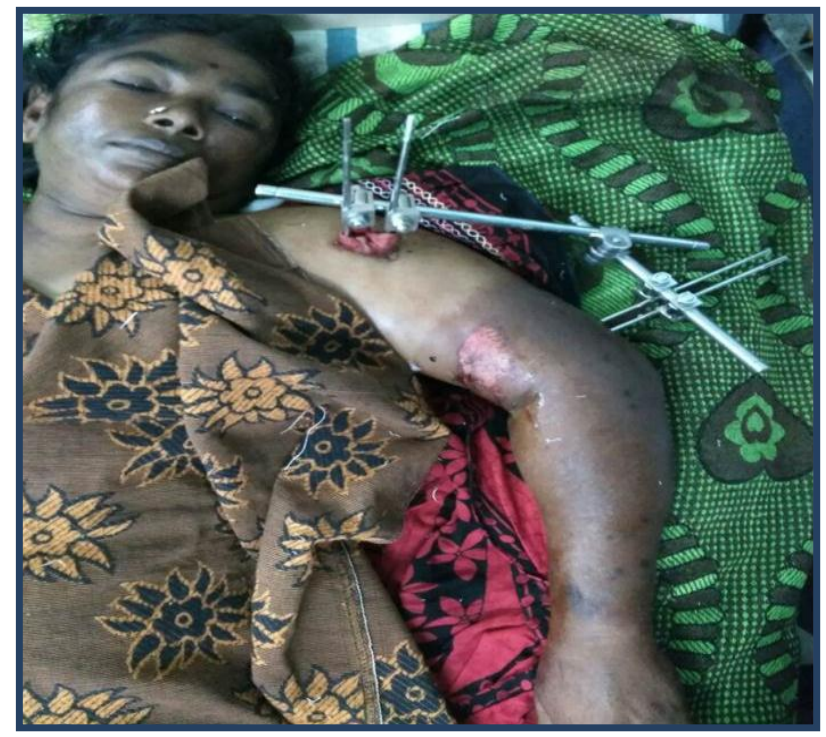

Figure 3: Modular external fixator insitu.

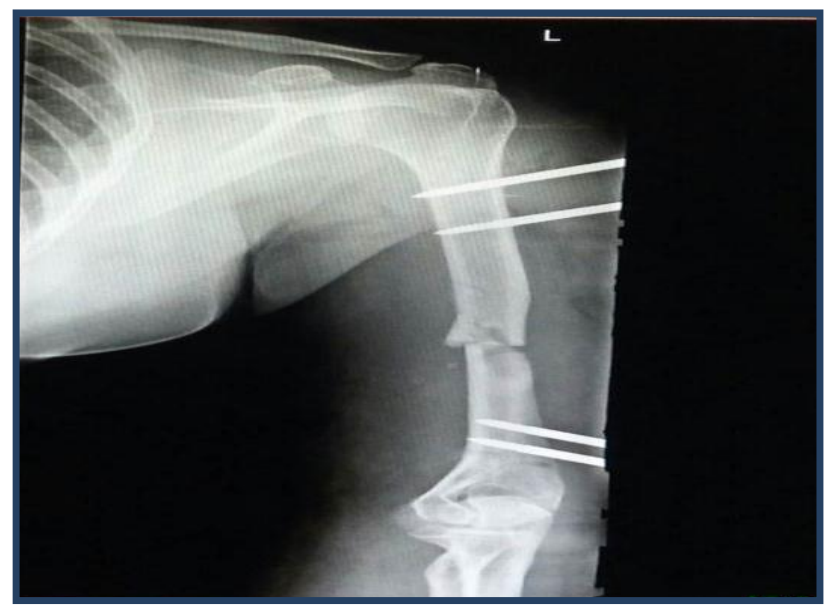

Figure 4: X-ray showing good alignment of fracture.

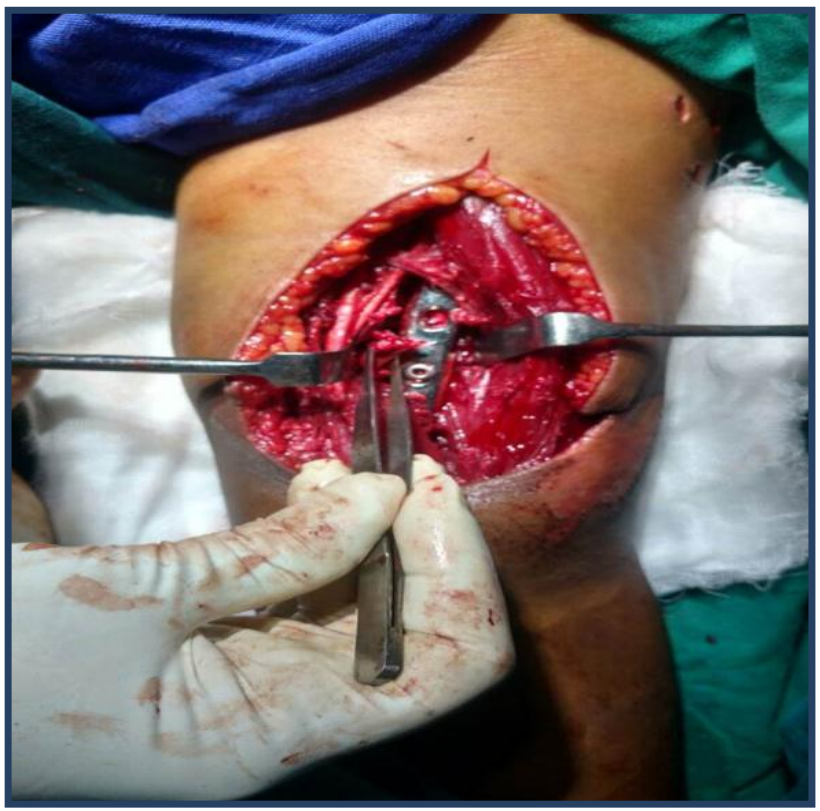

Figure 5: Fixation and bone grafting.

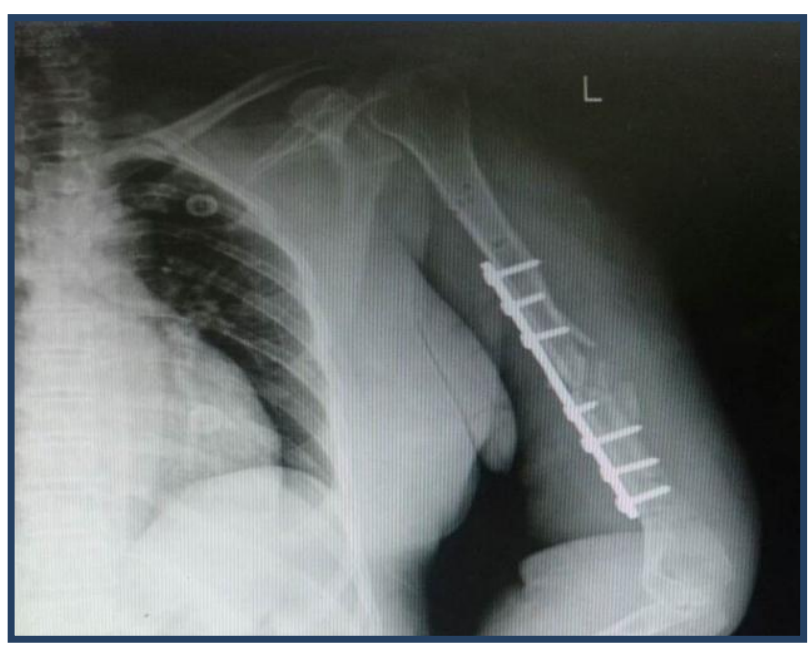

Fig 6: X-ray showing plate insitu. 
Colour doppler done after skeletal stabilization revealed low velocity biphasic flow in radial, ulnar and brachial arteries. Colour doppler on second day revealed low velocity biphasic flow in brachial artery at its bifurcation, and monophasic flow in radial and ulnar arteries. CT angiogram on day three revealed no contrast opacification in lower two-thirds of brachial artery, and reformatted flow in radial and ulnar arteries.

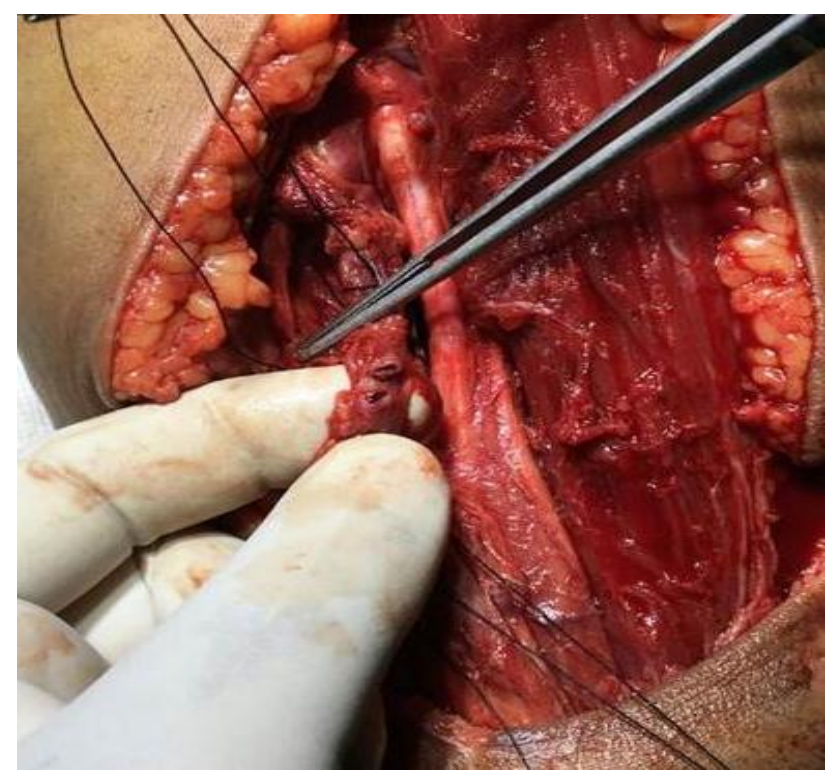

Figure 7: Complete transection of brachial artery.

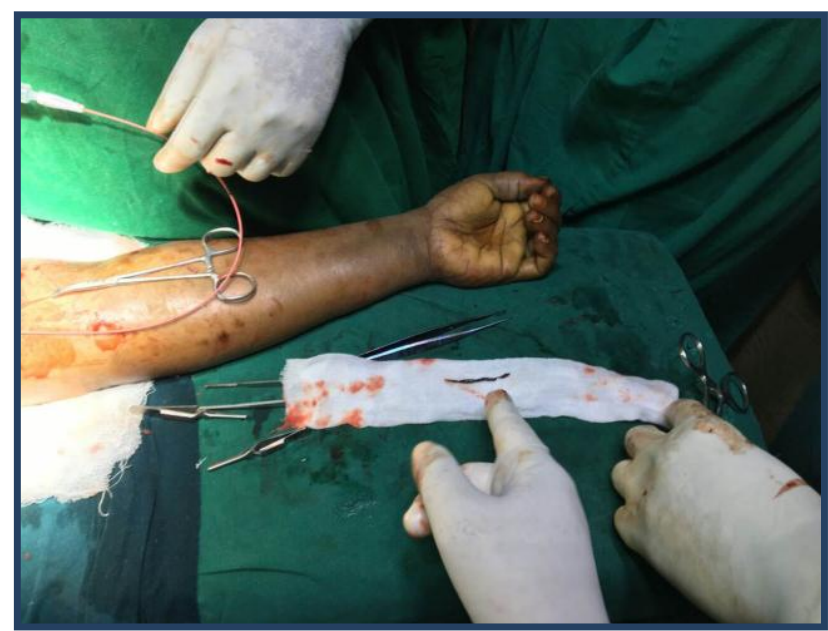

Figure 8: Thrombectomy using Fogarty's catheter.

Now the vascular surgeon was prompted to explore the brachial artery. Internal fixation of the fracture along with bone grafting was done first (Figure 5 and 6), followed by vascular procedure. The brachial artery was found to be completely transected at its middle third lower third junction (Figure 7). Thrombectomy was done using Fogarty's catheter (Figure 8). End to end anastamosis of brachial artery was done.
IV infusion of inj.Heparin (15,000 IU in $500 \mathrm{ml}$ of normal saline at $13 \mathrm{drops} / \mathrm{min}$ ) was administered for the next 4 days. Colour Doppler done on sixth post-operative day revealed no flow in brachial artery along with triphasic flow in ulnar artery and no flow in radial artery. After $6^{\text {th }}$ post-operative day, anticoagulants were given orally. (T.acitrom $2 \mathrm{mg}$ od, T.Aspirin $75 \mathrm{mg}$ od and T. clopidogrel $75 \mathrm{mg}$ od). The elbow was mobilized after suture removal.

\section{RESULTS}

Colour doppler done after 6 weeks of vascular repair revealed no flow in brachial (distal to the site of repair) and radial arteries and biphasic flow in ulnar artery. Digital Subtraction Angiography done at this stage showed no opacification in brachial artery distal to the origin of profunda brachii artery. Collaterals were seen in the cutaneous and intramuscular compartments of arm. Ulnar artery was opacified with contrast (indicating flow) (Figure 9).

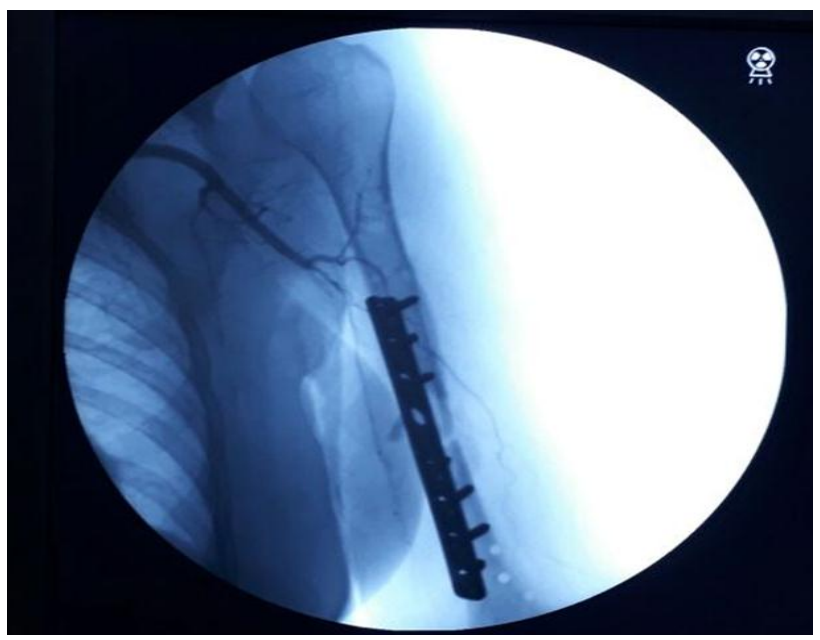

Figure 9: Image of digital substraction angiography showing flow through collateral circulation.

\section{DISCUSSION}

Ischemia after vascular injury can occur due to either transection of vessel or intravascular thrombosis or both. Incidence of brachial artery injury is the third most common (20\%) arterial injury after popliteal and femoral arterial injuries. ${ }^{4}$

According to Ekim et al, beyond a golden period of 6 to 8 hours after ischemia, ischemia reperfusion injury will endanger the viability of the limb. ${ }^{5}$ Moini et al studied 27 patients with delayed presentation of $31 \pm 3$ hours after brachial artery injury in whom brachial artery repair was done and 26 limbs were salvaged. ${ }^{6}$ They encountered ischemic nerve injuries in $20 \%$ of patients. They concluded that arterial repair is recommended even after the golden hour has lapsed, due to the possibility of revascularization because of extensive collateral circulation. 
Krishnan et al studied 45 patients with delayed presentation of $25+/-4$ hours after vascular injury involving upper and lower limbs in whom vascular repair was done and $89 \%$ of limbs were salvaged. ${ }^{4}$ Functional outcome was influenced more by the nature and pattern of injury rather than ischemic time. They concluded that early detection and revascularisation is important but delayed revascularisation also produces acceptable salvage outcomes.

Degree of ischemia after brachial artery injury depends on whether the injury is proximal or distal to profunda brachii. The infrequent need for amputation was probably related to the rich collateral circulation in the upper limb particularly in injuries distal to profunda brachii.

Several studies show that the survival of the limb in cases with transection or thrombosis of any major artery of upper or lower limbs is possible due to extensive collateral circulation around the injured arteries. ${ }^{4,5,7,8}$ In our case also, the limb survived because of collateral circulation through the profunda brachii artery.

There is a controversy whether to perform vascular repair followed by bony stabilization or vice versa. The standard recommendation is for vascular repair to precede fracture management. ${ }^{5,9}$ With an unstable bony injury, fracture fixation is done prior to vascular repair. ${ }^{10}$

External fixation has been increasingly preferred to stabilize the fracture. ${ }^{5,10}$ The advantages of external fixation are a) less operative time b) less tissue destruction c) less potential for infection in contaminated wound d) it allows daily debridement and irrigation.

Among the various investigations to diagnose vascular injury, angiography is the gold standard. ${ }^{7}$ However, this has its own disadvantages like time delay in shifting the patient to radiology department, expensive, etc. The alternative is doppler USG which has sensitivity of $95 \%$ and specificity of $92 \%$. The easy availability and noninvasive nature are considered as the advantages of this procedure. However, Doppler USG may show flow in the vessel distal to injury, whereas $\mathrm{CT}$ angiogram in the same patient may show cutting of flow at level of injury. This is because of collateral circulation. In our case also, we encountered a similar vascular flow pattern.

Therefore many studies have recommended arterial repair even after the patient presents after golden time of 6 hours, provided there is no evidence of gangrene. ${ }^{4,6,10}$

\section{CONCLUSION}

In patients presenting after the critical golden time of vascular injury, performing vascular repair along with use of systemic anticoagulants (and fasciotomy, if necessary) can salvage several limbs from amputation, due to the presence of collateral circulation. Moreover time should not be wasted in doing several diagnostic tests, which will only prolong the ischemia time.

\section{ACKNOWLEDGEMENTS}

We acknowledge the assistance rendered by the Department of vascular surgery and Department of radiology in the various stages of treatment.

Funding: No funding sources

Conflict of interest: None declared

Ethical approval: Not required

\section{REFERENCES}

1. Subasi M, Cakir O, Kesemenli C, Arslan H, Necmioglu S, Eren N. Popliteal artery injuries associated with fractures and dislocations about knee. Acta Orthop Belg. 2001;67:259-66.

2. Gustilo RB, Mendoza RM, Williams DN. Problems in the management of type III (severe) open fractures: a new classification of type III open fractures. J Trauma. 1984;24:742-6.

3. Dar AM, Ahanger AG, Wani RA, Bhat MA, Lone GN, Shah SH. Popliteal artery injuries: the Kashmir experience. J Trauma. 2003;55:362-5.

4. Jagdish K, Paiman M, Nawfar AS, Nawfar MI, Nawfar W, Nawfar WS, et al. The Outcomes of Salvage Surgery for Vascular Injury in The Extremities: A Special Consideration For Delayed Revascularization. Malaysian Orthop J. 2014;8(1):14-9.

5. Ekim H, Tuncer M. Management of traumatic brachial artery injuries: a report on 49 patients. Ann Saudi Med. 2009;29:105-9.

6. Majid M, Kaveh H, Rasouli MR, Mohsen N. Outcome of delayed brachial artery repair in patient with traumatic brachial artery injury:. Prospective study. Int J of Surg. 2008;(6):20-2.

7. Pezeshki Rad M, Mohammadifard M, Ravari H, Farrokh D, Ansaripour E, Saremi E. Comparing Color Doppler Ultrasonography and Angiography to Assess Traumatic Arterial Injuries of the Extremities. Iranian J Radiol. 2015;12(1):e14258.

8. Hunt CA, Kingsley JR. Vascular injuries of the upper extremity. South Med J. 2000;93:466-8.

9. McHenry TP, Holcomb JB, Aoki N, et al. Fractures with major vascular injuries from gunshot wounds: implications of surgical sequence. J Trauma. 2002;53:717-21.

10. Cakir O, Subasi M, Erdem K, Eren N. Treatment of vascular injuries associated with limb fractures. Ann R Coll Surg Engl. 2005;87:348-52.

Cite this article as: Ramprasath DR, Kamalanathan MK, Maheswaran KS, Muthsamy MP. Limb salvage after delayed arterial repair in compound Grade III C fracture humerus: a case report. Int J Res Orthop 2017;3:1231-4. 